\title{
Mutual influences and trends of Global Economic Growth and Global Mergers and Acquisitions
}

\author{
Shide Feng ${ }^{1,2, a}$ Zhaokai Wang ${ }^{3, b}$ \\ ${ }^{1}$ School of Economics (Faculty), Faculty of Political Science, Lomonosov Moscow State University, Lenin mountain \\ No.1, Moscow Russia Federation \\ ${ }^{2}$ Country Faculty of Political Science, Moscow state institute of international relations, Ave. Vernadskogo, 76, Moscow, \\ Russia Federation \\ ${ }^{3}$ Zhong Rong Trust, CGB Building, No.15, Jingsi St., Jinan 250002, China. Jinan. China
}

\begin{abstract}
The paper is to analyze the relationship between Global Economic Growth and Global Mergers and Acquisitions. After applying empirical analysis, conclude that Global Economic Growth and Global Mergers and Acquisitions have mutual influences on each other in the long-term period. In the short-term period, the results show the same trend. But in some short certain periods like rapid economic recessions, the trend shows the other way around. The paper also analyzes the economic intuitions of the mutual influences.
\end{abstract}

\section{INTRODUCTION}

The mergers and acquisitions are critical parts of the business world. On the microscope, there are lots of case studies and research shows that the mergers and acquisitions the enterprises' financial status and operation efficiency of the enterprises every year, which generally increases the outputs of enterprise indeed. And Surely, mergers and acquisitions influence the Global economic growth, on the macroscope level. This paper examines the relationship between Global Economic Growth and Global Mergers and Acquisitions, Analytical methods contains qualitative analysis and quantitative analysis, and empirical analysis.

\section{LITERATURE REVIEW}

Doytch \& Cakan (2011) examined the impact of acquisitions sales and mergers (M\&A) activities on economic [1], they use Generalized Method of Moments (GMM) estimator, concluded that financial and nonfinancial domestic services M\&A have a positive effect on services growth, and it may contribute the global economic growth.

Wang \& Wang (2011) found a stable long-term relationship between economic growth and enterprise mergers and acquisition [2]. In their study, they proposed the Vector Auto-Regression model that estimates the influence of macroeconomic indicators on the mergers and acquisitions.
Caldwell \& Smith (2011) introduced the interaction effects of the perspectives of enterprise [3], and how these interaction effects actually impact the output of the enterprise.

Li (2011) conducted an empirical study based on mergers and acquisitions theories to analyze the influence of macroeconomic indicators on the perspective of mergers and acquisitions [4], there are connections between business cycle and acquisitions sales and mergers (M\&A) activities.

\section{DATA}

Three types of data were selected and presented in this study. Among these data, the "global merger and acquisition" is represented by the global total number of M\&As cases and the total value of the global M\&As value (billion USD); and, the global economic growth is represented by the global economic growth. 


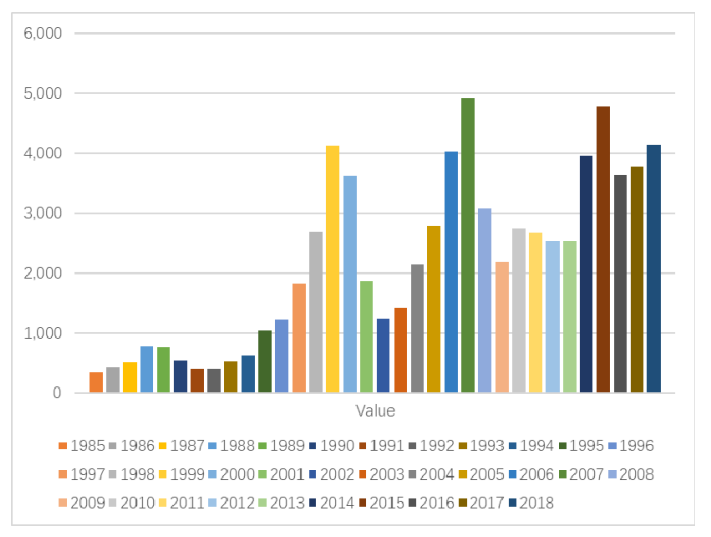

Fig. 1 Total Number of Merger and Acquisition Cases

As shown in Figure 1, the total numbers and corresponding values of M\&As cases have been keeping growing in the past decades (see Figure $1 \& 2$ ). The most significant points were observed in 1999 and 2007 when the financial crisis happened. The data description is as follows.

TABLE I. Data Description of Total Number of MERGER AND ACQUISITION CASES

\begin{tabular}{|c|c|c|c|}
\hline & Average & Midian & Midian \\
\hline Tot. Qty. of M\&As & 0130.82 & 32000 & 15462.21 \\
\hline \multicolumn{3}{|c|}{ Source: Author's estimation }
\end{tabular}

TABLE II. DATA Description OF TOTAL NUMBER OF MERGER AND ACQUISITION CASES

\begin{tabular}{|c|c|c|c|}
\hline & min. & $\max$. & obs. \\
\hline Tot. Qty. of M\&As & 2676 & 53302 & 34 \\
\hline
\end{tabular}

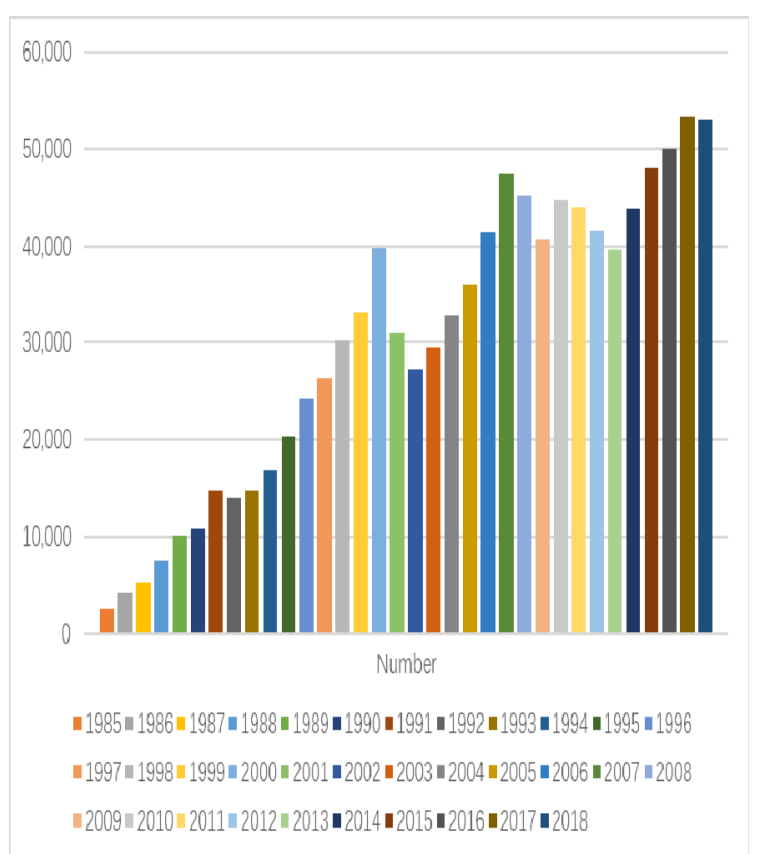

Fig. 2 Total Volume of Merger and Acquisition Cases

As shown in Figure 2, the numbers of M\&As activities reached 4,116 and 4,920 with corresponding growth in the total volume of 39,783 billion USD and
47,455 respectively. In 2014 , the increase in oil prices led to the new economic recession that caused millions of corporates word-widely to suffer from bankruptcy. This economic recession stimulated the growth of M\&As activities which reached 53,302 billion USD by the total volume of the M\&As activities. The data description is as follows.

TABLE III. DATA TOTAL Volume OF MERGER AND ACQUiSITION CASES

\begin{tabular}{|c|c|c|c|}
\hline & Average & Midian & Midian \\
\hline Tot. Vol. of M\&As & 2183.61 & 2166 & 1443.5 \\
\hline \multicolumn{3}{|c|}{ Source: Author's estimation }
\end{tabular}

TABLE IV. DATA DESCRIPTION OF TOTAL VOlume OF MERGER AND ACQUISITION CASES

\begin{tabular}{|l|c|c|c|}
\hline & min. & $\max$. & obs. \\
\hline TTot. Vol. of M\&As & 347 & 4920 & 34 \\
\hline
\end{tabular}

Source: Author's estimation

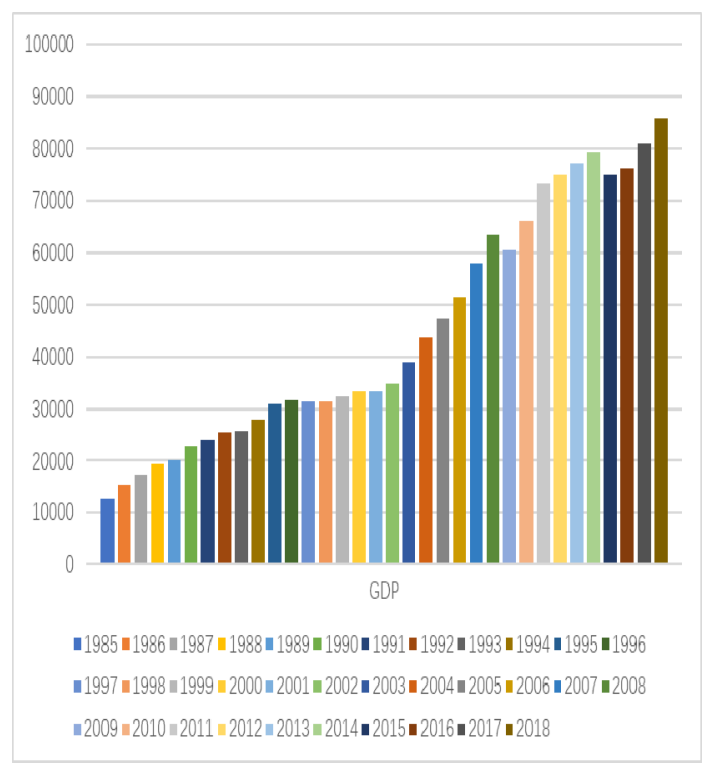

Fig. 3 Total Volume of Merger and Acquisition Cases

As shown in Figure 3, the global economic growth is keeping growing, it increases relitively fastly between 2001 to 2008 and 2011 to 2014 . The data description is as follows.

TABLE V. DATA DESCRIPTION OF THE GLOBAL ECONOMIC GROWTH (BILLION USD)

\begin{tabular}{|c|c|c|c|}
\hline & Average & Midian & Midian \\
\hline Global GDP & 44752.56 & 34125 & 22881.94 \\
\hline \multicolumn{4}{|c|}{ Source: Author's estimation }
\end{tabular}

TABLE VI. DATA DESCRIPTION OF TOTAL VOLUME OF THE GLOBAL ECONOMIC GROWTH (BILLION USD)

\begin{tabular}{|c|c|c|c|}
\hline & min. & max. & obs. \\
\hline Global GDP & 12786 & 85804 & 34 \\
\hline \multicolumn{3}{|c|}{ Source: Author's estimation }
\end{tabular}




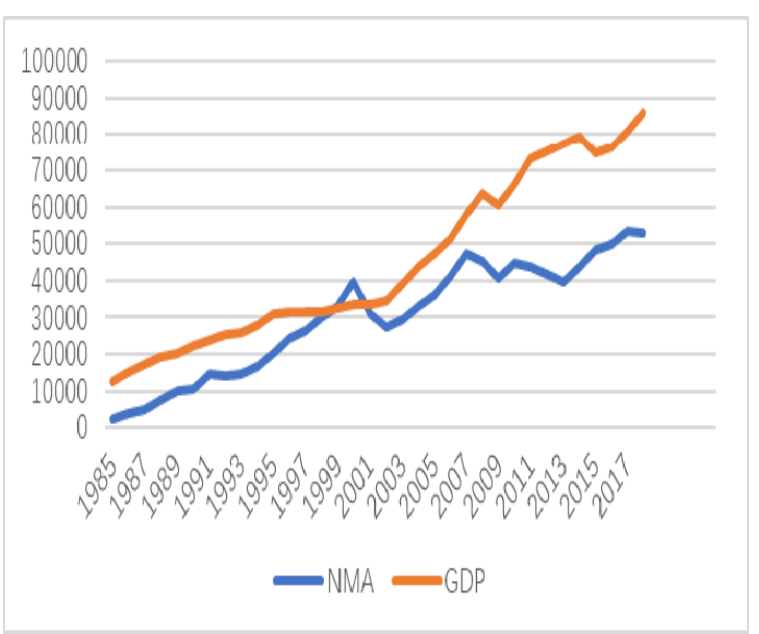

Fig. 4 Total Number of Merger and Acquisition Cases (billion USD) and Global Economic Growth (billion USD)

As shown in Figure 4, the total numbers and corresponding values of M\&As cases have been keeping growing in the past decades (see Figure $1 \& 2$ ). The most significant points were observed in 1999 and 2007 when the financial crisis happened. The numbers of M\&As activities reached 4,116 and 4,920 with corresponding growth in the total volume of 39,783 billion USD and 47,455 respectively. In 2014 , the increase in oil prices led to the new economic recession that caused millions of corporates word-widely to suffer from bankruptcy. This economic recession stimulated the growth of M\&As activities which reached 53,302 billion USD by the total volume of the M\&As activities.

\section{Model \& Estimation Results}

The estimated regression model was tested in RStudio, which is given as below:

Model 1:

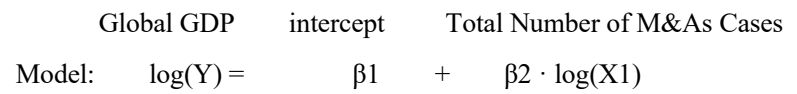

Model 2:

Global GDP intercept Total Volumn of M\&As Cases Model: $\log (\mathrm{Y})=\quad \beta 1+\beta 2 \cdot \log (\mathrm{X} 2)$

TABLE VII. DATA DESCRIPTION OF TOTAL VOLUME OF MERGER AND ACQUISITION CASES

\begin{tabular}{|c|c|c|c|}
\hline $\boldsymbol{\beta}$ & Estimate & $\boldsymbol{P}$-Value & $\begin{array}{c}\text { Significanc } \\
\boldsymbol{e}\end{array}$ \\
\hline$\beta 0$ (Intercept) & 4.1 & 0.561 & Yes \\
\hline$\beta 1$ (Tot. Qty. of M\&As) & 0.64 & 0.05 & Yes \\
\hline
\end{tabular}

Source: Author's estimation

TABLE VIII. DATA DESCRIPTION OF TOTAL Volume OF MERGER AND ACQUISITION CASES

\begin{tabular}{|c|c|c|c|}
\hline $\boldsymbol{\beta}$ & Estimate & P-Value & Significance \\
\hline$\beta 0($ Intercept) & 6.57 & 0.44 & Yes \\
\hline
\end{tabular}

\begin{tabular}{|c|c|c|c|}
\hline $\boldsymbol{\beta}$ & Estimate & P-Value & Significance \\
\hline$\beta 1$ (Tot. Qty. of M\&As) & 0.54 & 0.06 & Yes \\
\hline \multicolumn{2}{|c|}{ Source: Author's estimation }
\end{tabular}

The summarized significance test (T-test) results for Model 1 and Model 2 are presented in Table 7 and Table 8 above. The estimated result of Model 1 shows that other variables remain unchanged, every 1 percent increase in the Total Number of M\&As Cases, the global economic growth increases by 0.64 percent. The estimated result of Model 2 indicates that every 1 percent increase in the Total Volume of M\&As Cases, the global economic growth increases by 0.54 percent. The Rsquared for both models significantly illustrate the high accuracies of our statistical estimation. The estimated models were examined and approved statistically meaningful by the autocorrelation test and heteroscedasticity test.

\section{Conclusion}

In the long- term period, the general trend is that the merger and acquisition and global economic growth positively influence each other. Similarly, there are some microscope effects supporting this clear trend as follows, which are examined by the industries.

According to the observations, we also found that there are some certain short-term periods presented negative correlations between the merger and acquisition (M\&As) and global economic growth. However, once the rapid economic recession, i.e., financial crises, occurs, the merger and acquisition (M\&As) and global economic growth show the negative correlation, because the corporates may face bankruptcies during the recession, so the unstable company might start the merger and acquisition processes.

The cost synergies exist in several aspects, for example, operations, administration, and marketing. In the perspective of operation, when cost synergies increase purchasing power and eliminate the manufacturing and distribution redundancies. In regard to administration, the cost synergies may eliminate the overlapping part of the administration of companies, the excess of room expense of administration and other redundancy. In terms of marketing, it combines the sale channels and markets. Revenue synergies could offer incremental growth in four ways, depending on the mix of new and current markets and relevant involved products. Accumulation of these effects will lead to the economic growth.

\section{APPENDIX}

\begin{tabular}{|c|c|c|c|}
\hline Year & $\begin{array}{c}\text { Total } \\
\text { Number of } \\
\text { Merger and } \\
\text { Acquisition }\end{array}$ & $\begin{array}{c}\text { Total } \\
\text { Number of } \\
\text { Merger and } \\
\text { Acquisition }\end{array}$ & $\begin{array}{c}\text { The Global } \\
\text { economic } \\
\text { growth }\end{array}$ \\
\hline 1985 & 2676 & 347 & 12786.869 \\
\hline 1986 & 4228 & 435 & 15109.518 \\
\hline 1987 & 5279 & 506 & 17186.317 \\
\hline 1988 & 7440 & 777 & 19226.665 \\
\hline 1989 & 10135 & 758 & 20068.921 \\
\hline
\end{tabular}




\begin{tabular}{|c|c|c|c|}
\hline 1990 & 10814 & 540 & 22603.206 \\
\hline 1991 & 14722 & 397 & 23942.385 \\
\hline 1992 & 14102 & 400 & 25425.855 \\
\hline 1993 & 14772 & 516 & 25838.198 \\
\hline 1994 & 16816 & 624 & 27753.091 \\
\hline 1995 & 20278 & 1039 & 30865.108 \\
\hline 1996 & 24310 & 1217 & 31549.409 \\
\hline 1997 & 26227 & 1824 & 31435.986 \\
\hline 1998 & 30218 & 2678 & 31367.309 \\
\hline 1999 & 33132 & 4116 & 32529.37 \\
\hline 2000 & 39783 & 3623 & 33581.572 \\
\hline 2001 & 31047 & 1866 & 33382.422 \\
\hline 2002 & 27201 & 1242 & 34669.305 \\
\hline 2003 & 29573 & 1411 & 38899.897 \\
\hline 2004 & 32953 & 2145 & 43811.772 \\
\hline 2005 & 36025 & 2794 & 47459.061 \\
\hline 2006 & 41407 & 4023 & 51442.676 \\
\hline 2007 & 47455 & 4920 & 57968.742 \\
\hline 2008 & 45173 & 3075 & 63616.066 \\
\hline 2009 & 40710 & 2187 & 60340.071 \\
\hline 2010 & 44844 & 2750 & 66036.932 \\
\hline 2011 & 43976 & 2668 & 73357.42 \\
\hline 2012 & 41480 & 2533 & 75045.654 \\
\hline 2013 & 39568 & 2536 & 77189.608 \\
\hline 2014 & 43847 & 3960 & 79296.108 \\
\hline 2015 & 48052 & 4779 & 75003.074 \\
\hline 2016 & 49991 & 3646 & 76102.831 \\
\hline 2017 & 53302 & 3777 & 80891.341 \\
\hline 2018 & 52912 & 4134 & 85804.391 \\
\hline
\end{tabular}

\section{REFERENCE}

1. N. Doytch and E Cakan , "Growth effects of mergers and acquisitions: a sector-level study of OECD countries," Journal of Applied Economics and Business Research, vol. 1(3), pp. 120 129, 2011.

2. Y. Wang and X. Wang, "Macroeconomic factors that influencing corporate mergers and acquisitions," Jilin Finance Research, Vol 9 , pp. $10-15,2011$.

3. E. C. john and S. Ken, Overseeing Mergers and Acquisitions: The Elements of Style, 3rd. ed, Chartered Professional Accounts of Canada, vol. 1, pp. 20-80, 2011.

4. J. Li, "The influence of Macroeconomics environment on Mergers and Acquisition," Journal of Economics and Management, Vol 1, pp. 87-88, 2014. 